Florida International University

FIU Digital Commons

Electrical and Computer Engineering Faculty

Publications

College of Engineering and Computing

6-10-2019

\title{
Nanocomposite Bienzymatic Sensor for Monitoring Xanthine in Wound Diagnostics
}

Sohini RoyChoudhury

Yogeswaran Umasankar

Pulak Bhushan

Penelope A. Hirt

Flor E. MacQuhae

See next page for additional authors

Follow this and additional works at: https://digitalcommons.fiu.edu/ece_fac

Part of the Electrical and Computer Engineering Commons

This work is brought to you for free and open access by the College of Engineering and Computing at FIU Digital Commons. It has been accepted for inclusion in Electrical and Computer Engineering Faculty Publications by an authorized administrator of FIU Digital Commons. For more information, please contact dcc@fiu.edu. 


\section{Authors}

Sohini RoyChoudhury, Yogeswaran Umasankar, Pulak Bhushan, Penelope A. Hirt, Flor E. MacQuhae, Luis J. Borda, Hadar A. Lev-Tov, Robert Kirsner, and Shekhar Bhansali 
OPEN ACCESS

Nanocomposite Bienzymatic Sensor for Monitoring Xanthine in Wound Diagnostics

To cite this article: Sohini RoyChoudhury et al 2019 J. Electrochem. Soc. 166 B3295

View the article online for updates and enhancements. 


\title{
Nanocomposite Bienzymatic Sensor for Monitoring Xanthine in Wound Diagnostics
}

\author{
Sohini RoyChoudhury, ${ }^{1}{ }^{1, *}$ Yogeswaran Umasankar, ${ }^{\circledR 2, * *}$ Pulak Bhushan, ${ }^{1}$ \\ Penelope A. Hirt, ${ }^{3}$ Flor E. MacQuhae, ${ }^{3}$ Luis J. Borda, ${ }^{3}$ Hadar A. Lev-Tov, ${ }^{3}$ Robert Kirsner, ${ }^{3}$ \\ and Shekhar Bhansali $\circledast^{1, * *, z}$
}

\author{
${ }^{1}$ Department of Electrical and Computer Engineering, Florida International University, Miami, Florida 33174, USA \\ ${ }^{2}$ Biomolecular Sciences Institute, Florida International University Miami, Florida 33199, USA \\ ${ }^{3}$ Department of Dermatology and Cutaneous Surgery, University of Miami Miller School of Medicine, Miami, Florida \\ 33125, USA
}

\begin{abstract}
This work reports a biosensor for monitoring xanthine for potential wound healing assessment. Active substrate of the biosensor has xanthine oxidase (XO) and horseradish peroxidase (HRP) physisorbed on a nanocomposite of multiwalled carbon nanotubes (MWCNT) decorated with gold nanoparticles (AuNP). The presence of HRP provided a two-fold increase in response to xanthine, and a three-fold increase in response to the nanocomposite. With a sensitivity of $155.71 \mathrm{nA} \mu \mathrm{M}^{-1} \mathrm{~cm}^{-2}$ the biosensor offers a detection limit of $1.3 \mu \mathrm{M}$, with linear response between $22 \mu \mathrm{M}$ and $0.4 \mathrm{mM}$. Clinical sample analyses showed the feasibility of xanthine detection from biofluids in a lesion site due to diffusion of the analyte into surrounding biofluids. Higher concentrations by three-fold were observed from wound proximity, than away from injury, with an average recovery of $110 \%$. Results show the feasibility of monitoring wound severity through longitudinal measurements of xanthine from injured vicinity.

(C) The Author(s) 2019. Published by ECS. This is an open access article distributed under the terms of the Creative Commons Attribution 4.0 License (CC BY, http://creativecommons.org/licenses/by/4.0/), which permits unrestricted reuse of the work in any medium, provided the original work is properly cited. [DOI: 10.1149/2.0401909jes]

(cc) BY
\end{abstract}

Manuscript submitted February 19, 2019; revised manuscript received May 13, 2019. Published June 10, 2019. This paper is part of the JES Focus Issue on 4D Materials and Systems.

Inefficient management of wounds leads to delayed healing and, in some cases, surgeries and amputations. ${ }^{1}$ Delays in effective treatment can cause acute wounds to turn chronic, leading to hospital stays and readmissions with prolonged and expensive post-surgical care. This leads to larger healthcare costs and, in turn, a reduced quality of life. While technological advances are aiming to improve wound care, convenient wound therapy remains a significant challenge. Conventional wound-care techniques are limited to patients visiting the clinic to allow visual inspection of their wounds by clinical staff within twenty-four hours of occurrence; following up with timely referrals to therapy as appropriate. Although considerable methods have been undertaken to improve wound diagnostics, it is still challenging to precisely quantify how much a wound has healed. Solutions in existing wound-care include Aranz Medical's ${ }^{2}$ monitor and Ekare Inc., which use optical approaches to map the surface are of the wound and track tissue recovery across the scarred surface. ${ }^{3,4}$ However, such practices are possible only at the time of dressing change and do not offer information on wound dynamics in real-time. There are gaps yet to be filled in practices for both qualitative and quantitative wound-care.

A necessary factor for therapy consideration is examination of the wound bed and its physical measurements through wound boundary analysis and exudate evaluation. Efforts have been directed to monitor wound milieu parameters such as $\mathrm{pH}$, temperature, moisture, oxygen flow and antimicrobial activity. ${ }^{5}$ Continuous wound monitoring such as conceptualizing the simultaneous monitoring of $\mathrm{pH}$ and temperature of a wound bed, is being explored. ${ }^{6}$ This is achieved through investigations of the human purine metabolic pathway. Monitoring the biochemical activity of the pertaining analytes aids in leveraging biochemical detection of wound severity. Among the different biomarkers used to determine lesion severity, xanthine is known as an inflammatory biomarker capable of forming reactive oxygen species (ROS) such as hydrogen peroxide $\left(\mathrm{H}_{2} \mathrm{O}_{2}\right)$, which promotes healing. Such species act as scavengers of oxygen radicals to facilitate tissue recovery. In the case of cell rupture, xanthine is formed in the wound

\footnotetext{
*Electrochemical Society Student Member

**Electrochemical Society Member.

${ }^{\mathrm{z}}$ E-mail: sbhansa@ fiu.edu
}

(localized xanthine) from the breakdown of released energy of metabolites in the tissue. Increased purine degradation and apoptosis increases the concentrations of such purine metabolites. Smart bandages utilize electrochemical approaches to determine wound severity through biochemical monitoring of analytes. Different multi-dimensional materials and nanotechnology are being extensively explored for the purpose of designing smart, wearable medicinal platforms. Such materials include carbon, silver, gold and soft, flexible biomaterials (biocompatible polymers and hydrogels) to investigate infection control and promote healing. ${ }^{7-10}$ These materials claim to assist in providing an enhanced and stable sensing response to analytes, which can be correlated with the healing of wounds.

Possible biofluids that can be explored to monitor a wound include those from in and around an injury. Bio-analytes from wound exudate tend to attain equilibrium with extracellular fluids such as interstitial fluid, which is transported to neighboring glands. Fluid oozes in and around the wound through diffusion in the internal dermal and subcutaneous layers of skin and surrounding blood vessels. ${ }^{11}$ This occurs due to the differences in osmotic gradients of the metabolites and components in the biofluids. With elevated xanthine concentrations at the injury site, its vicinity also has a rise in level. Normal physiological concentrations of xanthine $(65-130 \mu \mathrm{M})^{12}$ are elevated to higher levels in and around a wound. Therefore, biomarkers that have a correlation with wound healing and its severity can be utilized for analysis of tissue recovery through their detection from biofluids in wound proximity.

In this work, an electrochemical sensor for detection of xanthine in biofluids of wound exudate and from around the wound has been presented. Sensor functionalization using two enzymes, XO and horseradish peroxidase (HRP), notably improved the sensing response from facilitated electron transfer between the analyte and the transducer. Biofluid sample studies from in and around the wound provided insights into the physiological concentrations of xanthine in and around an injury. Such detection provides a potential noninvasive method for the quantification of lesion severity. Through the utilization of existing cellular biochemical pathways, this work illustrates the viability of an electrochemical approach for detection of wound severity through direct longitudinal measurements of such biomarkers. 


\section{Experimental}

Materials.-XO lyophilized powder containing $7 \mathrm{U} \mathrm{mg}^{-1}$ was purchased from Sigma Aldrich and used for xanthine oxidation. XO enzyme immobilization was performed on screen-printed carbon electrodes (SPCE) purchased from $\mathrm{CH}$ Instruments, Inc., United States. 0.2 $\mathrm{U} \mathrm{ml}^{-1} \mathrm{HRP}$ of analytical grade was used from ThermoFisher Scientific. MWCNT (o.d. $=10-20 \mathrm{~nm}$, i.d. $=2-10 \mathrm{~nm}$ and length $=0.5-200 \mu \mathrm{m}), 20 \mathrm{~nm} \mathrm{Au}$ nanoparticles $(0.5 \mu \mathrm{M})$, and dimethylformamide (DMF) were purchased from Sigma Aldrich. Xanthine, sodium hydroxide $(\mathrm{NaOH})$, hydrogen peroxide $\left(\mathrm{H}_{2} \mathrm{O}_{2}\right)$, sodium phosphate monobasic $\left(\mathrm{NaH}_{2} \mathrm{PO}_{4}\right)$ and sodium phosphate dibasic $\left(\mathrm{Na}_{2} \mathrm{HPO}_{4}\right)$ were used of analytical grade. All aqueous solutions were prepared using deionized (DI) water. Phosphate buffer solutions (pH 5 to 8) (20 mM) were prepared using $\mathrm{NaH}_{2} \mathrm{PO}_{4}$ and $\mathrm{Na}_{2} \mathrm{HPO}_{4}$ salts and were used as electrolyte solutions. Colorimetric Xanthine assay kits were purchased from Sigma Aldrich and utilized to analyze clinical samples.

Apparatus and methods.-The working electrode was functionalized with MWCNT prepared in DMF by drop-casting and drying at $60^{\circ} \mathrm{C}$, followed by AuNP and drying at $60^{\circ} \mathrm{C}$. The working electrodes were modified with $20 \mu \mathrm{g} \mathrm{cm}^{-2}$ MWCNT and $0.5 \mu \mathrm{M}$ AuNP $(1: 1 \mathrm{~V} / \mathrm{V})$. Electrode surface characterization was performed using SEM JEOL 6330. The nano-material functionalized electrodes were further modified with the enzyme catalysts $0.2 \mathrm{U} \mathrm{ml}^{-1} \mathrm{XO}$ and $0.2 \mathrm{U}$ $\mathrm{ml}^{-1}$ HRP. The ratio of MWCNT:AuNP functionalization was optimized with $1: 1,1: 2,2: 1,1: 3$ and $3: 1 \mathrm{~V} / \mathrm{V}$. It was seen that higher current response was obtained from $1: 1$ as compared to other ratios (inset: Fig 3b), owing to uniform distribution of MWCNT:AuNP across the electrode surface. Lower response from increased amounts of AuNP across the MWCNT decorated surface can be attributed to reduced electrode surface area, from coverage of the pores on the carbon substrate. ${ }^{13}$ Higher amounts of MWCNT were noted to provide increased capacitance with a small difference in faradaic current. ${ }^{14}$ The mixtures of XO and HRP at different molar ratios in PBS (1:1, $1: 2,2: 1,1: 3,3: 1)$ were used to immobilize the enzymes onto the MWCNT/AuNP modified electrodes. The amounts of XO and HRP $\left(0.2-0.6 \mathrm{U} \mathrm{ml}^{-1}\right)$ were optimized to obtain improved electron transfer. It was seen that 1:1 ratio of XO:HRP $\left(0.2 \mathrm{U} \mathrm{ml}^{-1}\right)$ provided higher signal as compared to the other bi-enzymatic electrodes (inset: Fig 3b). Reduced current response in higher enzyme ratios can be ascribed to either lower production of $\mathrm{H}_{2} \mathrm{O}_{2}$ from decreased amounts of $\mathrm{XO}$, or due to reduced electron transfer from lesser amounts of HRP. ${ }^{15}$ This shows that $1: 1$ ratio $\left(0.2 \mathrm{U} \mathrm{ml}^{-1} \mathrm{XO}: \mathrm{HRP}\right)$ provided optimum catalytic response.

All enzyme immobilizations were achieved through drop casting, nitrogen drying, and rinsing in PBS to remove un-entrapped enzymes prior to testing. Drying in nitrogen allowed for the removal of excess water from the electrode surface, forming a gel like structure. ${ }^{16}$ Physical adsorption of the enzyme on the electrode surface was a simple and cost-effective method of immobilization, whereby the enzyme attached to the working electrode surface through van-derWaal's forces. ${ }^{17-19}$ All steps involving the enzymes were carried out in an ice-box to reduce enzyme denaturation. Cyclic voltammetry (CV) was performed using the analytical system model CHI230B potentiostat from CH Instruments, Inc. Standard electrochemical characterizations were carried out in a classical three-electrode system consisting of SPCE, an external $\mathrm{Ag} / \mathrm{AgCl}$ as reference electrode, and a Pt counter electrode. This three-electrode system was tested in an electrochemical cell setup with a $3 \mathrm{~mL}$ electrolyte solution to assess the performance of the nanomaterial-enzyme functionalized electrode in different concentrations of xanthine at a $\mathrm{pH}$ of 7.8. These measurements were performed at $20 \mathrm{mV} \mathrm{s}^{-1}$ to record the generated $\mathrm{H}_{2} \mathrm{O}_{2}$ at the cathode between $-0.1 \mathrm{~V}$ and $-0.6 \mathrm{~V}$. The effect of $\mathrm{pH}$ on the functionalized sensors was also studied using different $\mathrm{pH}$ solutions (5-10). Control studies were performed in the absence and presence of different nanomaterials (MWCNT and $\mathrm{Au}$ ) with the working electrode being infused with the enzymes

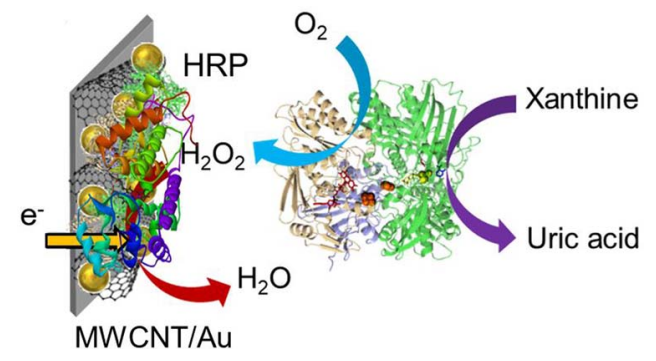

Figure 1. Schematic showing electron transfer mechanism in xanthine oxidation by $\mathrm{XO}$ and HRP on a nanocomposite functionalized electrode.

XO and HRP. The electrodes tested were (i) bare, (ii) XO/HRP, (iii) $\mathrm{Au} / \mathrm{XO} / \mathrm{HRP}$, (iv) MWCNT/XO/HRP, (v) MWCNT/Au/XO/HRP, (vi) $\mathrm{MWCNT/Au/XO}$ and (vii) MWCNT/Au/HRP. The effect of $\mathrm{pH}$ on enzyme activity was recorded using an Evolution 201 UV-Visible Spectrophotometer, ThermoFisher Sc. The ThermoFisher Sc. microplate absorbance reader was used to conduct assay experiments.

Xanthine extraction from wound dressing.-Five de-identified wound dressing samples were collected for xanthine extraction from patients at the wound clinic in University of Miami. Each dressing, about $10 \mathrm{~cm} \times 10 \mathrm{~cm}$, was collected from the patient's injured leg at the time of their dressing change. The wound dressings were carefully cut to $5 \mathrm{~cm} \times 5 \mathrm{~cm}$, as shown in Fig 2, to extract the biofluid that diffused through the dressing. Each of these samples were immersed in a $\mathrm{NaOH}$ solution prepared in DI water $(\mathrm{pH} 12)$ and incubated at $37^{\circ} \mathrm{C}$ for forty-five minutes. They were then ultra-sonicated in a homogenizer for $60 \mathrm{~s}$ at $20 \mathrm{~Hz}$ to extract the samples from the dressings. The extracted solutions of wound exudate and those from perilesional and healthy skin were tested on the biosensor. Assays for correlating concentrations of xanthine in the different samples were conducted using standard colorimetric assay protocol at $570 \mathrm{~nm}$.

\section{Results and Discussion}

Enzymatic reaction mechanism and sensor performance.-Xanthine dehydrogenase is prevalent in normal tissue and transforms to $\mathrm{XO}$ in the case of injury. $\mathrm{XO}$ is an oxidoreductase enzyme with a cofactor, flavin adenine dinucleotide (FAD), that facilitates its oxidation to a terminal purine product, uric acid (UA). XO has 2 molecules of FAD bridged by a pair of ferric mercaptide groups. ${ }^{20}$ Purine substrates bound by the isoalloxazine ring system of one FAD undergoes oxidation in presence of $\mathrm{O}_{2}$ and $\mathrm{H}_{2} \mathrm{O}$ (Eq. 1). The presence of a molybdenum cofactor in $\mathrm{XO}$ allows for the transfer of electrons in the oxidation pathway to convert to by-product $\mathrm{H}_{2} \mathrm{O}_{2}$. This oxidation pathway of xanthine, as illustrated in Fig. 1, was utilized in this study, with the enzymes acting as natural catalysts to facilitate detection. The enzymatic oxidation of xanthine was quantified by measuring the formed $\mathrm{H}_{2} \mathrm{O}_{2}$ on the electrode. Electrochemical analyses showed that $\mathrm{XO}$ provided an onset potential of $-0.3 \mathrm{~V}$ in presence of xanthine with no defined reduction peak (Fig 3a). This was due to sluggish reduction in the XO functionalized substrate.

$$
\text { Xanthine }+\mathrm{O}_{2}+\mathrm{H}_{2} \mathrm{O} \rightarrow \text { Uric acid }+\mathrm{H}_{2} \mathrm{O}_{2}
$$

$$
\text { Horseradish peroxidase }+\mathrm{H}_{2} \mathrm{O}_{2} \rightarrow \mathrm{H}_{2} \mathrm{O}+\mathrm{O}_{2}
$$

To facilitate the reduction of $\mathrm{H}_{2} \mathrm{O}_{2}$ on the electrode, HRP was introduced in the study. HRP, being a metalloenzyme, has an iron heme group and contains a histidine residue, which is in a vacant resting site. ${ }^{21} \mathrm{H}_{2} \mathrm{O}_{2}$ can attach to this vacant site during its reductionoxidation reactions, where an oxygen atom can bind during activation. This position is considered as the active site for enzyme binding. ${ }^{21}$ The presence of HRP facilitated the electron transport of $\mathrm{H}_{2} \mathrm{O}_{2}$. It can be observed from Eq. 2 that HRP catalyzes the reduction of $\mathrm{H}_{2} \mathrm{O}_{2}$ to 

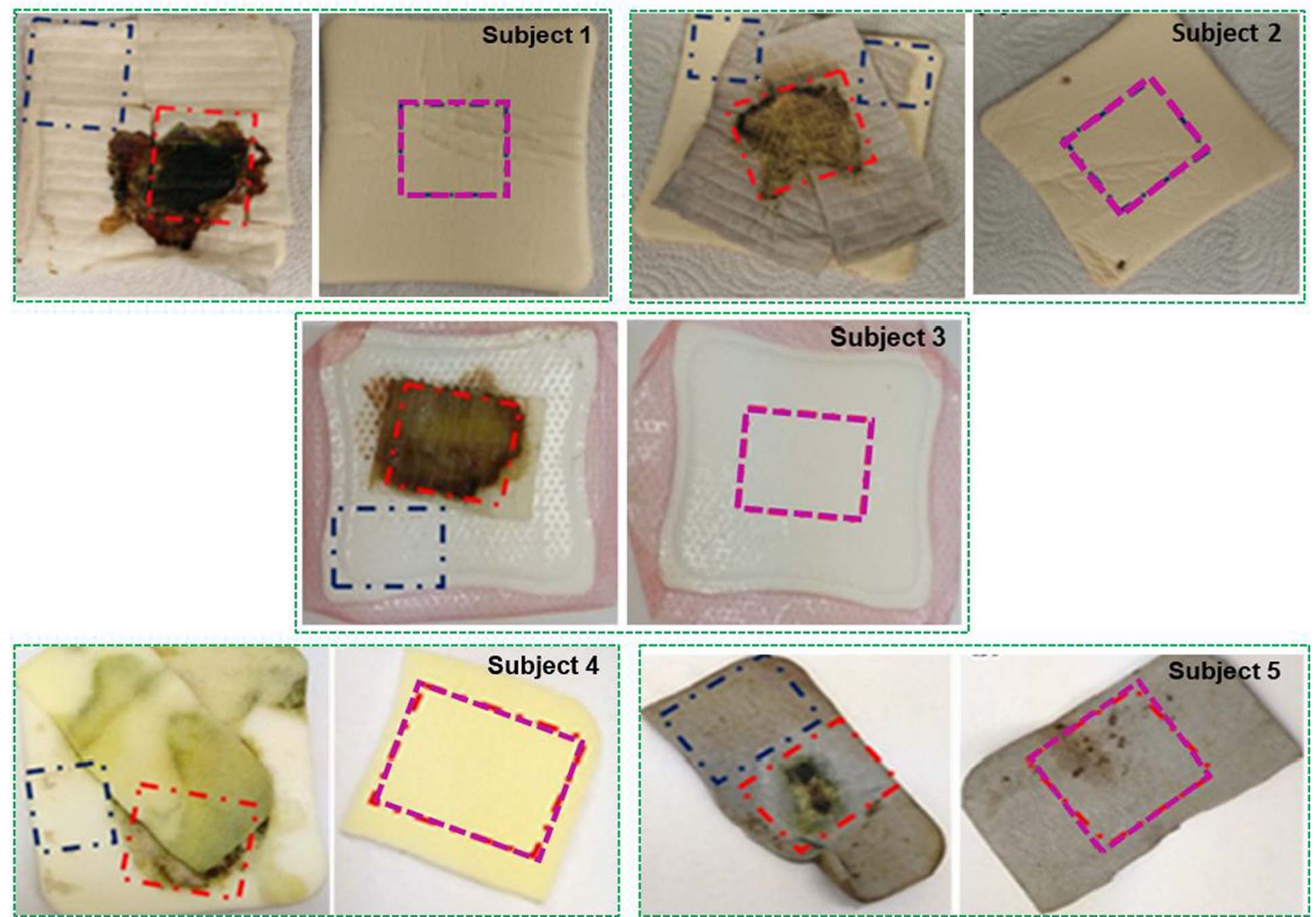

Figure 2. De-identified wound dressings from 5 patients, subjects $1-5$ respectively are shown by green dashed lines (- - -); red dashed lines (- - -) represent the extraction area of wound exudate; blue dashed lines (- - -) represent the extraction area of biofluid from perilesional skin and pink dashed lines (- - -) represent healthy skin extracted area.
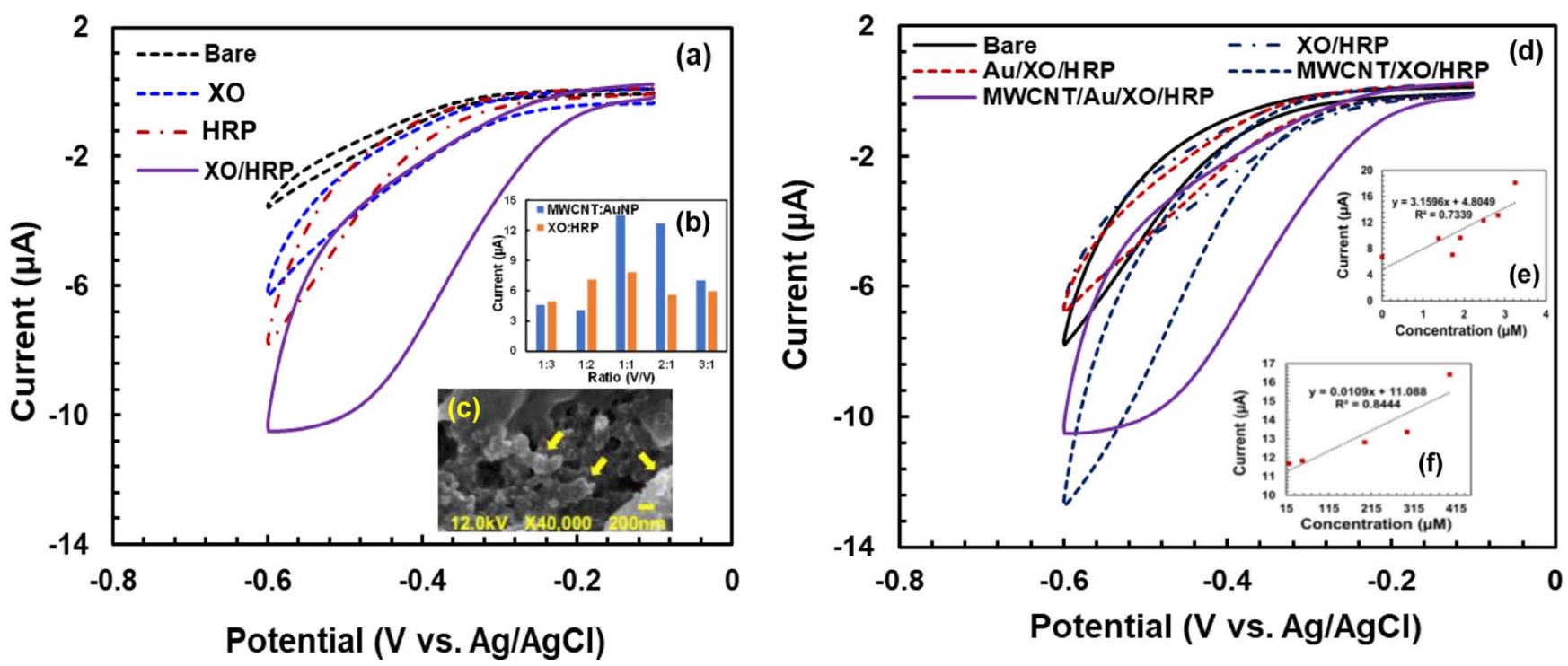

Figure 3. (a) CV signals of bare, MWCNT/Au functionalized with $\mathrm{XO}$ or $\mathrm{HRP}$ or both in presence of $32 \mu \mathrm{M}$ xanthine; Insets: (b) Plot depicting change in response with varied MWCNT/AuNP and XO/HRP functionalization in presence of $32 \mu \mathrm{M}$ xanthine; (c) SEM micrograph of MWCNT/Au electrode surface; (d) CV signals of bare, XO/HRP electrodes with MWCNT or Au or MWCNT/Au in presence of $32 \mu \mathrm{M}$ xanthine; Insets: (e) Linear regression plot of the bi-enzymatic sensor, (f) Linear regression plot of the sensor at elevated concentrations. 
water and oxygen. The presence of HRP was noted to improve electron transport by facilitating the rapid transfer of electrons between the enzyme and the transducer. This enabled increased reduction of $\mathrm{H}_{2} \mathrm{O}_{2}$, in turn offering amplified signal output with improved quantification for biomarker detection. ${ }^{22,23}$ The presence of HRP increased the current density by $71.42 \mu \mathrm{A} \mathrm{cm}^{-2}$ at an $E \mathrm{p}_{\mathrm{c}}=0.5 \mathrm{~V}$ in presence of xanthine. This electrode also displayed lower onset potential $(0.2 \mathrm{~V})$ compared to a single enzymatic electrode. This indicates improved electrocatalytic activity. In comparison, a bare electrode shows no definite peak due to no formed $\mathrm{H}_{2} \mathrm{O}_{2}$. The bi-enzymatic electrode was thus seen to show an enhanced response to the same concentration of xanthine. The use of such physiologically relevant enzymes allows them to act as natural catalysts in detection. Utilizing such enzymes allows for improved electrocatalytic activity with specific response to the target analyte.

To enable electron transfer between the electrode and the analyte, a nanocomposite of MWCNT and Au nanoparticles was investigated in detection. The presence of isolated MWCNT or Au nanomaterial on the enzymatic electrode did not provide any defined peak in the presence of xanthine (Fig. 3d). A MWCNT functionalized enzymatic electrode provided a 2 -fold increase in signal as compared to $\mathrm{Au}$ nanoparticle modified electrode. The presence of a combination of MWCNT and Au nanocomposite offered a further enhanced response from the enzymatic electrode at a low onset potential of $0.3 \mathrm{~V}$. An increase in current signal by $7 \mu \mathrm{A}$ was observed at an $E \mathrm{p}_{\mathrm{c}}=0.5 \mathrm{~V}$ with a lower onset potential of $0.2 \mathrm{~V}$.

Electrochemical response from the nanocomposite electrode was evaluated in the presence of increasing concentrations of xanthine in the physiologically relevant range. Typical concentrations of xanthine are known to vary between 3 and $5 \mu \mathrm{M}$ in healthy individuals with therapeutic levels rising from 35 to $160 \mu \mathrm{M}^{24,25}$ Sensor response employing nanomaterials of MWCNT and Au was evaluated within $6 \mu \mathrm{M}$ (inset: Fig 3e) and elevated concentrations (inset: Fig 3f). Sensor design employing nanomaterials of MWCNT and Au assisted in providing a linear response between $22 \mu \mathrm{M}$ and $0.4 \mathrm{mM}$ (inset: Fig 3f), broader than the physiological range. With a detection limit of $1.3 \mu \mathrm{M}$, enhanced performance was recorded (inset: Fig $3 \mathrm{e}$ ). An increase in $I \mathrm{p}_{\mathrm{c}}$ was recorded when subjected to different increasing concentrations of xanthine within the physiologically relevant range. This nanocomposite modified bi-enzymatic electrode offered a sensitivity of $155.71 \mathrm{nA} \mu \mathrm{M}^{-1} \mathrm{~cm}^{-2}$ through irreversible immobilization of the enzyme on the working area. An improved response was obtained in the presence of increased concentrations of xanthine due to increased reduction of $\mathrm{H}_{2} \mathrm{O}_{2}$ on the nanomaterial functionalized bi-enzymatic sensor. The SEM micrograph (inset: Fig 3c) depicts the surface distribution of $\mathrm{Au}$ nanoparticles decorated over MWCNT on the active substrate. The combination of these two different kinds of nanostructures offered a larger surface area for improved enzyme loading (inset: Fig 3a). The uniformly spread nanomaterial composite provided greater electrocatalytic activity ratios. ${ }^{26}$ This approach incorporating both enzymes, XO and HRP, in combination with the nanocomposite of MWCNT and Au nanoparticles allowed for improved quantification in biomarker detection. ${ }^{27,28}$

Effect of $\boldsymbol{p H}$.- Since physiological events are $\mathrm{pH}$-dependent, $\mathrm{pH}$ plays a role in the process of lesion healing. $\mathrm{pH}$ within the woundmilieu influences the biochemical reactions involved and is known to have a correlation with healing. It affects the cellular events involved in healing and plays an important role in determining infection control, antimicrobial activity, and oxygen release in recovery. The $\mathrm{pH}$ of an injured micro-environment is known to be alkaline with a value between 8 and 10, depending on wound severity and the healing phase. Chronic non-healing wounds are known to have an elevated alkaline $\mathrm{pH}(7.15$ to 8.9$)$. As a wound heals, the $\mathrm{pH}$ shifts from alkaline (7-9) to acidic, the normal $\mathrm{pH}$ of skin (4-6). ${ }^{16,29-30}$ Therefore, the enzymatic response in different $\mathrm{pH}$ conditions was explored.

Enzymes are reportedly sensitive to $\mathrm{pH}$ and can denature over time with $\mathrm{pH}$ variations. They provide stable performance with retained activity at specific pH levels. ${ }^{31} \mathrm{XO}$ is known to be active at a slightly

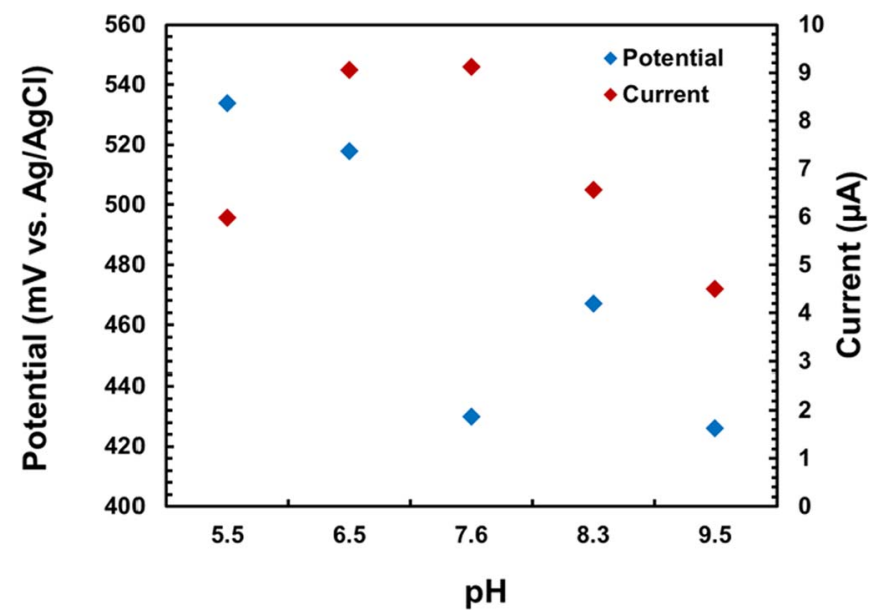

Figure 4. Effect of $\mathrm{pH}$ on the current and potential of the bi-enzymatic sensor in presence of xanthine.

alkaline $\mathrm{pH}(7.5-7.8)$, with a pKa value of 6.5 and an isoelectric point around $\mathrm{pH} 6{ }^{32,33} \mathrm{HRP}$ is known to provide an optimum response around $\mathrm{pH}(6-6.5)$ with a $\mathrm{pKa}$ and isoelectric point of 6.4 and 7.2, respectively. ${ }^{34,35}$ To understand the activity of XO/HRP in the mixture and assess the electrochemical activity, the bi-enzymatic sensor was analyzed over a $\mathrm{pH}$ range from 5.5 to 9.5. It was observed that higher response was obtained between $\mathrm{pH} 7$ and 8 (Fig. 4). An increased current was obtained at $\mathrm{pH} 7.5$ at a low $E \mathrm{p}_{\mathrm{c}}$. There was a shift in the peak potential with reduced values as the $\mathrm{pH}$ changed from acidic to alkaline. As wounds are known to shift from a higher to a lower $\mathrm{pH}$ with healing, this correlation could potentially enable the calibration of the enzymatic biosensor as a tool for wound monitoring. These investigations offer an improved understanding of the $\mathrm{pH}$ environments suitable for enzymatic detection of xanthine. This shows that the bienzymatic sensor can provide responses in physiologically relevant $\mathrm{pH}$ ranges for wound assessment.

Interference studies.-Wound exudate has high protein content, comprising several electrolytes and inflammatory components. ${ }^{36}$ Analogy of acute wound fluid has previously shown the presence of different ions like sodium, potassium, chloride, urea and creatinine; besides other cytokines, leucocytes, lysozymes, macrophages, neutrophils and other microorganisms. Thus, biochemical analysis of a wound environment using an electrochemical biosensor may be affected by interference from such electroactive species. Among the wound fluid components, such species are hypoxanthine, uric acid, ascorbic acid and dopamine. Xanthine is produced from hypoxanthine and leads to the formation of uric acid in purine metabolism, using XO.

XO being the key catalyst in the biosensor, such purine metabolites are interferents in detection.

Like purine metabolites, the wide presence of electroactive species like ascorbic acid and dopamine in humans will also interfere with xanthine detection. Under physiological conditions, interference from hypoxanthine $(8 \mu \mathrm{M})$ and uric acid $(0.5 \mathrm{mM})$ were thus investigated, in the same potential window. It can be seen from Table II, that minimal change in response between $3.8 \%$ and $9.9 \%$ was observed with the presence of these interferents. With the presence of ascorbic acid (34 $\mu \mathrm{M})$, comparatively higher interference was noted, with a change in response by $11.8 \%$, while dopamine (196 pM) was seen to depict an interference of $8.8 \%$. Interferent concentrations were chosen as per the higher biological levels, with detection in presence of lower physiological concentrations of xanthine. This shows that even in presence of higher concentrations of the common electroactive interferents, the sensor signal for lowest concentration of xanthine does not deviate beyond $\pm 6 \%$. Thus, this enzymatic biosensor can be utilized to determine xanthine in biofluids. 

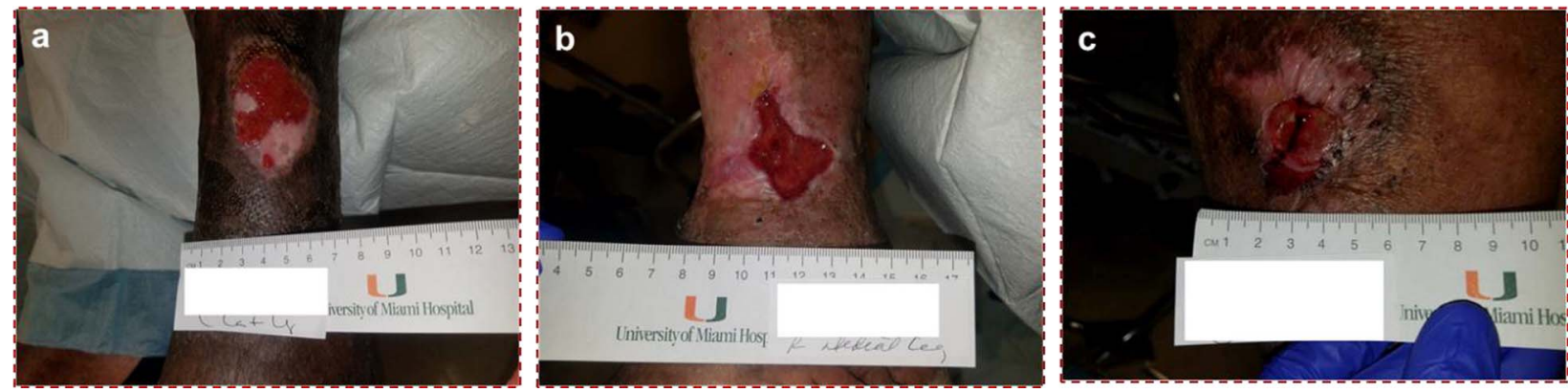

Figure 5. De-identified wound images of patients diagnosed with venous leg ulcers (a, b) and sickle cell disease leg ulcer (c).

Clinical sample analyses.-Venous leg ulcers and sickle cell disease leg ulcers of de-identified patients within a week of therapy were analyzed (Fig. 5). Therapy for such wounds is primarily compression and pressure oriented, to increase the venous return and reduce venous hypertension to allay the pressure damage caused in valves of leg veins. ${ }^{37,38}$ Analysis from these dressings showed, that the wound exudate from larger wounds $\left(14 \mathrm{~cm}^{2}\right)$ had $3.25 \mu \mathrm{M}$ xanthine compared to 2.77 and $1.85 \mu \mathrm{M}$ for wounds with smaller area of $5 \mathrm{~cm}^{2}$ and $1 \mathrm{~cm}^{2}$, respectively. Such a relationship suggests that a correlation may be drawn between wound severity and xanthine concentrations; ${ }^{39}$ wounds with a larger area contain higher concentrations of xanthine than smaller wounds. A correlation can be drawn between severe wounds depicting higher concentrations than healing wounds, with large wounds typically taking longer to heal. ${ }^{40,41}$ However, larger number of sample studies are necessary to validate the correlations. This work focuses on assessing the feasibility of the bi-enzymatic sensor for xanthine detection in the extracted biofluids from wound exudate, perilesional and healthy skin. Obtained sensor readings were validated against standard assay protocols. A correlation between the assay and sensor measurements was drawn in Table I. It can be seen from Table I that the biosensor readings have high deviations for wound exudate measurements as compared to measurements from perilesional and healthy skin. These deviations are reflected in their recovery values as seen in the same table, where wound exudate has $\sim 122 \%$ deviation, while extracts from perilesional and healthy skin have a deviation of only about $40.48 \%$ and $86.41 \%$, respectively. Different wounds contain varying levels of electrolytes and proteins. ${ }^{42}$ The deviation in response can also be ascribed to these differences in bio-fluid composition. This effect of biofluid occlusion on the active surface of the biosensor was studied through electrochemical analysis. It showed the rate of decrease in response to sequential deposition of extracts of wound exudate and biofluid from around the wound. The bi-enzymatic sensor showed a gradual decrease in response to extracts from perilesional and healthy skin with the same volume of analyte. As illustrated in Fig. 6, the rate of decrease in response to wound exudate is $20 \%$ more than when subjected to extracts around and away from the wound. This higher rate of decrease can be attributed to the occlusion of solid proteins, proteases, cytokines and neutrophils present in the wound exudate on the active area of the electrode. Such accumulation tends to block the electrode surface, limiting diffusion of analyte to the transducer and promoting electrode fouling. Measurements recorded over the sequential deposition of analyte have shown that the response of the bi-enzymatic electrode was reduced by only $10 \%$ in the presence of biofluid from healthy skin before attaining stability. It can thus be said that the bi-enzymatic sensor could potentially be utilized for wound healing therapy through assessment of xanthine from biofluids in injured vicinity.

To assess the ability to monitor xanthine from wound vicinity noninvasively, extracted biofluids from perilesional and healthy skin were measured, along with exudate extracted from the wound dressings

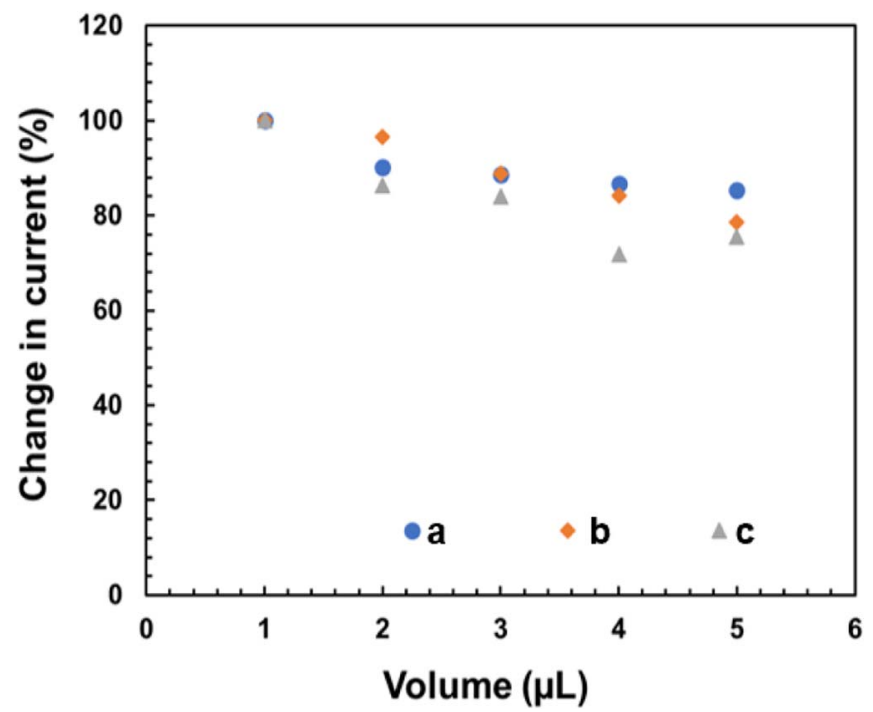

Figure 6. Percentage change in current response of the biosensor as a function of volume of extracted biofluids from healthy skin (a), perilesional skin (b) and wound exudate (c).

Table I. Detection of xanthine in extracted wound exudate, biofluid from perilesional and healthy skin of de-identified patients using the biosensor.

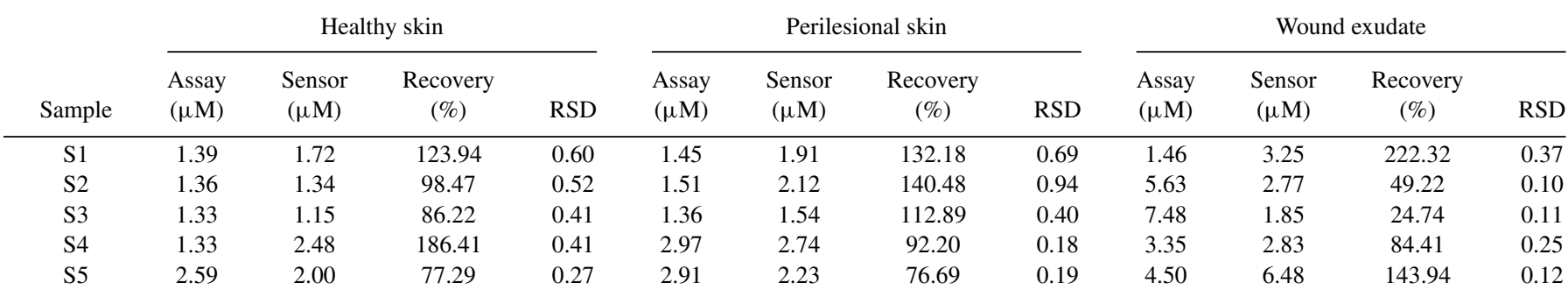


Table II. Response of sensor for $3 \mu \mathrm{M}$ xanthine in absence and presence of interfering biomolecules.

\begin{tabular}{ccccc} 
Interfering biomolecules & Interferent concentration $(\mu \mathrm{M})$ & $\begin{array}{c}\text { Response without interferent } \\
(\mu \mathrm{A})\end{array}$ & Response with interferent $(\mu \mathrm{A})$ & Change in response $(\%)$ \\
\hline Uric Acid & 500 & 12.05 & 13.25 \\
Hypoxanthine & 8 & 11.06 & 11.49 & 9.96 \\
Ascorbic Acid & 34 & 9.14 & 10.23 & 3.89 \\
Dopamine & 0.000196 & 15.51 & 16.88
\end{tabular}

of five different patients. The biosensor was utilized to electrochemically analyze the extracted bio-fluids and determine the concentrations of xanthine. Results obtained from this study have been depicted in Table I and Fig. 7. Analyte concentrations were observed to be higher from extracted wound exudate than from further away from the injury site. Biofluids from healthy skin showed comparatively lower concentrations. This indicates that concentrations of xanthine are higher in wound proximity and are reduced when further away from the lesion site. On the occurrence of a wound, fluid oozes in and around the punctured tissue by diffusing through glands and surrounding tissue through the internal, lower dermal layers of skin due to changes in osmotic gradients of the metabolites. ${ }^{5}$ Therefore, the area around the wound also has a rise in analyte concentrations. It can be seen from this study that measuring xanthine from biofluids in and around the injury of a person is possible and not at all cumbersome. This shall also allow to reduce occlusion effects from embedding the sensor directly on the wound.

\section{Conclusions}

A potentiometric biosensor was developed using two enzymes, $\mathrm{XO}$ and HRP, for non-invasive detection of xanthine from wound exudate and biofluids around a wound. Electrochemical analyses from nanomaterial modified bi-enzymatic electrodes provided enhanced responses with an increased reduction of by-product $\mathrm{H}_{2} \mathrm{O}_{2}$. Linear response was obtained with increasing concentrations of xanthine over the concerned physiological range. The nanomaterial functionalized bi-enzymatic electrode was used for the detection of xanthine from wound exudate and biofluid samples from perilesional and healthy skin. The viability of xanthine detection from wound milieu was explored through this study. Results have shown the feasibility of de-

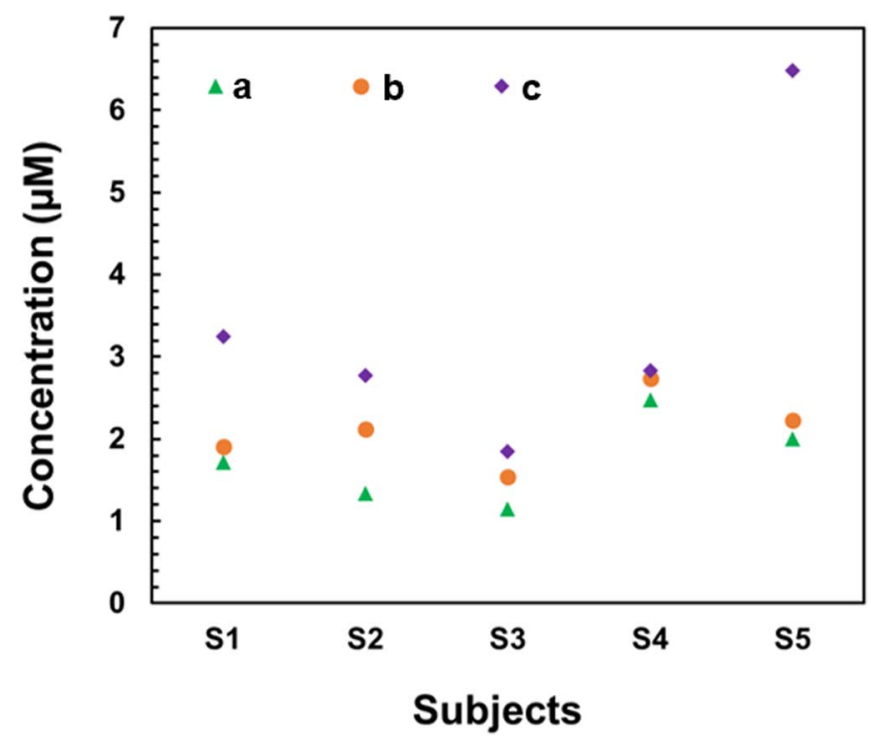

Figure 7. Concentrations of xanthine concentrations from extracts of biofluids sampled from healthy skin (a), perilesional skin (b) and wound exudate (c) of five de-identified patients using the biosensor. tection of xanthine from bio-fluid matrices around an injured region, with portrayed higher concentrations in wound proximity than further away. This work paves a potential path for the stable detection of purine metabolites from biofluids in and around the wound, allowing for the non-invasive assessment of lesion severity, providing insights on healing progress.

\section{Acknowledgments}

This work is being supported by the NSF Nanosystems Engineering Research Centre for Advanced Self-Powered Systems of Integrated Biosensors and Technologies (ASSIST) under Award Number EEC-1160483.

\section{ORCID}

Sohini RoyChoudhury (D) https://orcid.org/0000-0001-5169-8451 Yogeswaran Umasankar (D) https://orcid.org/0000-0001-9713-8548 Shekhar Bhansali (D) https://orcid.org/0000-0001-5871-9163

\section{References}

1. Z. Peng, J. Zhou, A. Dacy, D. Zhao, V. Kearney, W. Zhou, L. Tang, and W. Hu, J. Biomed. Opt., 22, 016010 (2017).

2. M. Nixon and C. Moore, Aranz Medical, (2014).

3. J. D. Bills, S. J. Berriman, D. L. Noble, L. A. Lavery, and K. E. Davis, Int. Wound J., 13, $1372(2016)$

4. E. L. Anghel, A. Kumar, T. E. Bigham, K. M. Maselli, J. S. Steinberg, K. K. Evans, P. J. Kim, and C. E. Attinger, Wounds, 28, 379 (2016).

5. S. RoyChoudhury, Y. Umasankar, J. D. Hutcheson, H. A. Lev-Tov, R. S. Kirsner, and S. Bhansali, Electroanalysis, 30, 2374 (2018).

6. P. Mostafalu, A. Tamayol, R. Rahimi, M. Ochoa, A. Khalilpour, G. Kiaee, I. K. Yazdi, S. Bagherifard, M. R. Dokmeci, B. Ziaie, S. R. Sonkusale, and A. Khademhosseini, Small, (2018).

7. M. F. Farooqui, \& A. Shamim, Nature Sc. Reports, 6, 28949 (2016).

8. J. Tian, K. K. Y. Wong, C. M. Ho, C. N. Lok, W. Y. Yu, C. M. Che, J. F. Chiu, and P. K. H. Tam, ChemMedChem, 2, 129 (2007).

9. T. Guinovart, G. Valdez-Ramirez, J. R. Windmiller, F. J. Andrade, and J. Wang, Electroanalysis, 26, 1345 (2014).

10. P. Mostafalu, W. Lenk, M. R. Dokmeci, B. Ziaie, A. Khademhosseini, and S. R. Sonkusale, IEEE Trans. Biomedical Circuits And Systems, 9, 670 (2015).

11. F. H. Epstein, W. M. Lee, and R. M. Galbraith, N. Engl. J. Med., 326, 1335 (1992).

12. S. H. Y. Wong, Therapeutic Drug Monitoring and Toxicology by Liquid Chromatography, p. 512 (2017)

13. L. Dumee, L. Velleman, K. Sears, M. Hill, J. Schutz, N. Finn, M. Duke, and S. Gray, Membranes, 1, 25 (2011)

14. D. Du, M. Wang, Y. Quin, and Y. Lin, J. Mater. Chem, 20, 1532 (2010).

15. W. Chen, S. Cai, Q. Q. Ren, W. Wen, and Y. D. Zhao, Analyst, 137, 49 (2012).

16. S. RoyChoudhury, Y. Umasankar, J. Jaller, I. Herskovitz, J. Mervis, E. Darwin, P. A. Hirt, L. J. Borda, H. A. Lev-Tov, R. S. Kirsner, and S. Bhansali, J. Electrochem. Soc., 165, B3168 (2018).

17. S. RoyChoudhury, Y. Umasankar, and S. Bhansali, Meet. Abstr., MA2018-03, 278 (2018).

18. N. R. Mohamad, N. H. C. Marzuki, N. A. Buang, F. Huyop, and R. A. Wahab, Biotechnol. Biotechnol. Equip., 29, 205 (2015).

19. N. An, C. H. Zhou, X. Y. Zhuang, D. S. Tong, and W. H. Yu, Appl. Clay Sci., 114, 283 (2015).

20. I. Fridovich and P. Handler, J. Biol. Chem, 231, 899 (1958).

21. Nigel C. Veitch, Phytochemistry, 65, 249 (2004).

22. V. Sanz, S. de Marcos, and J. Galbán, Anal. Chim. Acta, 607, 211 (2008).

23. D. Tang, R. Yuan, and Y. Chai, Anal. Chem., 80, 1582 (2008).

24. R. Kock, B. Delvoux, M. Sigmund, and H. Greiling, Eur. J. Clin. Chem. Clin. Biochem, 32, 837 (1994).

25. M. J. Cushley and S. T. Holgate, Thorax, 40, 176 (1985)

26. A. A. Ansari, M. Alhoshan, M. S. Alsalhi, and A. S. Aldwayyan, Sensors (Basel)., 10, 6535 (2010). 
27. K. Talley and E. Alexov, Proteins, 78, 2699 (2010).

28. G. Rocchitta, A. Spanu, S. Babudieri, G. Latte, G. Madeddu, G. Galleri, S. Nuvoli, P. Bagella, M. I. Demartis, V. Fiore, R. Manetti, and P. A. Serra, Sensors (Basel)., 16, 780 (2016).

29. T. R. Dargaville, B. L. Farrugia, J. A. Broadbent, S. Pace, Z. Upton, and N. H. Voelcker, Biosens. Bioelectron., 41, 30 (2013).

30. G. Gethin, Wounds UK, 3, 52 (2007).

31. R. Daniel, M. Dines, and H. H. Petach, Biochem. J., 317, 1 (1996).

32. E. G. Ballt, J. Biol. Chem., 128, 51 (1939).

33. M. Xia, R. Dempski, and R. Hille, J. Biol. Chem., 274, 3323 (1999).

34. J. Hernanndez-Ruiz, M. B. Arnao, A. N. P. Hiner, F. Garcia-Canovas, and M. Acosta, J. Biochem., 354, 107 (2001).
35. A. Maehly and B. Chance, Methods Biochem Anal, 1, 357 (1954).

36. K. F. Cutting, Br. J. Community Nurs., 8, S4 (2003).

37. S. Tate, A. Price, and K. Harding, BMJ, 361, k1604 (2018).

38. M. Briggs, E. A. Nelson, and M. Martyn-St James, Cochrane Database of Systematic Reviews, 11 (2012).

39. M. L. Fernandez, D. Stupar, T. Croll, D. Leavesley, and Z. Upton, Adv Wound Care, 7, 95 (2018).

40. P. Sheehan, P. Jones, A. Caselli, J. M. Giurini, and A. Veves, Diabetes Care, 26, 1879 (2003).

41. S. Coerper, S. Beckert, M. A. Küper, M. Jekov, and A. Königsrainer, J. Journal of Diabetes and Its Complications, 23, 49 (2009).

42. N. J. Trengove, S. R. Langton, and M. C. Stacey, Wound Repair Regen., 4, 234 (1996). 